\title{
Management of Important Endemic Diseases of Barnyard Millet (Echinochloa frumentacea L.) by the Use of Bio-Control Agents in Mid Hills of Uttarakhand, India
}

\author{
Laxmi Rawat $^{1 *}$, T.S. Bisht ${ }^{2}$, Shambhoo Prasad ${ }^{1}$, T. Samuel and S.K. Patro ${ }^{3}$ \\ ${ }^{1}$ College of Forestry, Ranichauri, Tehri Garhwal, V.C.S.G. Uttarakhand University of \\ Horticulture and Forestry, Bharsar, India \\ ${ }^{2}$ KVK, Ranichauri, Tehri Garhwal, V.C.S.G. Uttarakhand University of Horticulture and \\ Forestry, Bharsar, India \\ ${ }^{3}$ Agricultural Research Station, Gajularega, Vizianagaram-535 001, Andhra Pradesh, India \\ *Corresponding author
}

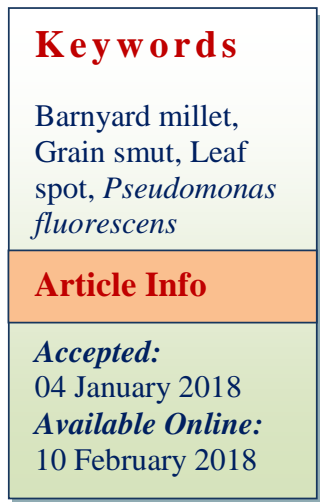

A B S T R A C T
A study was conducted to evaluate the potential of fluorescent Pseudomonas isolates against important endemic diseases of barnyard millet. A total of ten pseudomonad isolates, collected from rhizospheric soil samples of barnyard millet, were studied, out of which three fluorescent Pseudomonas isolates (UUHF Psf- 1, UUHF Psf-2 and UUHF Psf4) were selected for testing under heterogeneous field conditions on the basis of their in vitro performance against the conducted biocontrol traits viz., Phosphate solubilzation test Siderophore production test and $\mathrm{HCN}$ production test. A field experiment was thus carried out in a completely randomized block design with three replications and seven treatments including untreated control. Maximum grain smut disease control (91.92\%) and brown spot disease control (75.99) was recorded in the treatment T4 (Soil application of value added vermi-compost impregnated by fluorescent Pseudomonas isolate UUHF Psf- $4+$ Seed treatment with fluorescent Pseudomonas isolate UUHF Psf- 4 + One foliar spray with fluorescent Pseudomonas isolate UUHF Psf- 4 at the time of $50 \%$ flowering). Maximum grain yield (23.13 q/ha), highest per cent increase in grain yield $(64.86 \%)$ and highest per cent avoidable loss $(39.34 \%)$ was also recorded in the same treatment T4. Treatment T6 (Soil application of value added vermicompost impregnated by fluorescent Pseudomonas isolate UUHF Psf -1+ Seed treatment with fluorescent Pseudomonas isolate UUHF Psf- 1 + One foliar spray with fluorescent Pseudomonas isolate UUHF Psf- 1 at the time of $50 \%$ flowering) was next best treatment and recorded $70.96 \%$ grain smut disease control and $63.98 \%$ brown spot disease control, $32.77 \%$ avoidable los and $48.75 \%$ increase in grain yield over untreated control (T8). All the tested treatments were found economical and significantly superior in comparison to untreated control in suppressing the grain smut and brown spot diseases and enhancing the grain yield in Barnyard millet though the findings were better in treatment T4 in most of the parameters studied under present experimental conditions. This research merits attention and could additionally open the avenue for the use of above mentioned fluorescent Pseudomonas isolates in suppressing the most destructive diseases of Barnyard Millet at the mid hill regions of Uttarakhand. 


\section{Introduction}

Small Millets occupy unique position in hill agriculture. These are the crops of small and marginal farmers requiring little inputs. Probably no other crop withstands drought as efficiently as the small millets. Small millets are known for their resilience, which is helpful in adjusting to diverse ecological situations. Among the six small millets grown in India, finger millet, barnyard millet, foxtail millet and proso-millet are the major crops grown exclusively in Himalayan region at present. Little millet, though used to be grown earlier in some areas, is presently out of cultivation.

In Uttarakhand, Barnyard millet is grown over an area of about 66.09 thousand ha with annual production of 85.29 thousand tons (approx.) under rainfed conditions by the small and marginal farmers in difficult conditions of cultivation at the mid hill regions.

However, productivity of the crop is reduced due to a number of diseases. Grain smut and brown leaf spot caused by Ustilago panicifrumentacei and Helminthosporium crusgalli are two important diseases resulting in low productivity of the crop at the mid hill regions of Uttarakhand. Therefore, present investigation was carried out to identify sources other than chemicals which could provide resistance against these diseases in susceptible but locally preferred variety of Barnyard millet.

In recent years, attempts were also made to use a consortium of bio-control agents to get persistent control of plant pathogens (Chaube and Sharma, 2002; Rawat et al., 2011, 2012). The main objective of this study was therefore to evaluate the bio-control efficiency of native isolates of fluorescent pseudomonads against important endemic diseases of Barnyard millet.

\section{Materials and Methods}

\section{Collection of soil samples}

Rhizospheric soil samples were collected from healthy Barnyard millet plants cultivated in different farming situations from three districts of Garhwal region viz., Dehradun (Kalsi- Chakrata), Tehri and Rudraprayag. Plants were uprooted and cleaned of access soil. The top six-inch layer of soil surrounding the root system was removed and the soil adhering to the main roots and root hair was collected in pre-sterilized poly-bags. Samples were brought to the laboratory for the selective isolation of the fluorescent Pseudomonas spp.

\section{Seed material}

The Seed material for the present investigation comprised to var. VL 207 of Barnyard millet (Echinochloa frumentacea). The seed material used in study was obtained from Plant Pathology B- Block, College of Forestry, Ranichauri. The var. VL 207, though is highly susceptible to grain smut and leaf spot diseases however, it is highly preferred by the farmers in the hills of Uttarakhand.

\section{Selective isolation of fluorescent Pseudomonas spp}

For the selective isolation of fluorescent Pseudomonas isolates, 'serial dilution' technique was used. One gram of rhizospheric soil sample was suspended into $10 \mathrm{ml}$ sterilized distilled water and vortexed. One $\mathrm{ml}$ of the above suspension was aseptically transferred to pre-sterile water blank containing $9.0 \mathrm{ml}$ of distilled water. This process was repeated till the original suspension was diluted up to $10^{-9}$. One hundred $\mu$ l of the above dilution (from $10^{-3}$ to $10^{-9}$ ) were transferred on King's B medium plates and spread using glass spreader. Plates 
were then incubated at $28 \pm 2{ }^{\circ} \mathrm{C}$ for $48 \mathrm{~h}$. After incubation, plates were examined under UV-light and colonies giving yellow-green fluorescence were marked and selected. Individual colony was transferred to $\mathrm{KB}$ slants and again incubated at $28 \pm 2{ }^{\circ} \mathrm{C}$ for $48 \mathrm{~h}$. To ensure that only fluorescent Pseudomonas spp. were picked up, individual colonies were restreaked on King's B medium at least thrice since most colonies might comprise more than one morphotype. Mother cultures were maintained at $4^{\circ} \mathrm{C}$.

\section{Bacterial antagonists}

A total of 10 native isolates of fluorescent Pseudomonas spp. were isolated from rhizospheric soil samples of barnyard millet grown in different farming situations of Uttarakhand. The details of the host plant, location and isolated pseudomonads are given in Table 1. Those isolated fluorescent pseudomonads were then screened for different biocontrol traits.

\section{Evaluation for traits of bio-control activity of fluorescent Pseudomonas isolates}

\section{Evaluation for phosphate solubilization}

Solubilization of tricalcium phosphate was detected in Pikovskaya's Agar medium. Each isolate of fluorescent Pseudomonas spp. was streaked in Pikovskaya agar medium and incubated at $28 \pm 2{ }^{\circ} \mathrm{C}$ for $48 \mathrm{~h}$ (Rao, 1999). The development of clear zone around the colony indicated phosphate solubilizing activity.

\section{Evaluation for siderophore production}

Siderophore production by all the isolates was tested qualitatively by Chrome Azural S (CAS) plate assay (Schwyn and Neilands, 1987). For this test, etiolates with chrome azure $\mathrm{S}$ agar medium were prepared. Three to four Pseudomonas isolates (in one medium plate) were spot inoculated in triplicate and incubated at $28 \pm 2{ }^{\circ} \mathrm{C}$ for $72 \mathrm{~h}$. After incubation, plates were observed for an orange halo around the bacterial growth. Formation of yellow orange color zone around the colonies in plate assay indicated the siderophore production.

\section{Evaluation for $\mathrm{HCN}$ production}

Modified Millar and Higgins's method (1970) was used to evaluate all the isolates for $\mathrm{HCN}$ production. For this test, the isolates were line streaked on tryptic soy agar plates. Lids of the plates were lined with filter paper dipped in alkaline picric acid solution and the plates were incubated at $28 \pm 2{ }^{\circ} \mathrm{C}$ for 3-5 days. After incubation, plates were observed for change in color of filter paper from yellow to orange, brown or brick red, indicated positive reaction for $\mathrm{HCN}$ production.

\section{Field experiment}

Out of ten fluorescent pseudomonads, three fluorescent Pseudomonas isolates (UUHF Psf1, UUHF Psf-2 and UUHF Psf-4) were selected for testing under heterogeneous field conditions on the basis of their in vitro performance against the conducted biocontrol traits viz., phosphate solubilization test, siderophore production test and $\mathrm{HCN}$ production test. A field experiment was carried out in a completely randomized block design at Plant Pathology B-Block, College of Forestry, Ranichauri, Tehri Garhwal, with seven treatments and three replications. Plot size was maintained $3 \times 2.5 \mathrm{~m}^{2}$ with six rows of three meters in length. The details of the treatments are given below:-

\section{Treatment details}

$\mathrm{T} 1=$ Seed treatment with fluorescent Pseudomonas isolate UUHF Psf -4@ $10 \mathrm{~g} / \mathrm{kg}$ seed. 
$\mathrm{T} 2=$ Seed treatment with fluorescent Pseudomonas isolate UUHF Psf- 2 @ $10 \mathrm{~g} / \mathrm{kg}$ seed.

$\mathrm{T} 3=$ Seed treatment with fluorescent Pseudomonas isolate UUHF Psf -1 @ $10 \mathrm{~g} / \mathrm{kg}$ seed.

T4 = Soil application of value added vermicompost impregnated by fluorescent Pseudomonas isolate UUHF Psf- $4+$ Seed treatment with UUHF Psf -4 @ $10 \mathrm{~g} / \mathrm{kg}$ seed+ One foliar spray with UUHF Psf -4@ 10 g/L at the time of $50 \%$ flowering.

$\mathrm{T} 5=$ Soil application of value added vermicompost impregnated by fluorescent Pseudomonas isolate UUHF Psf- 2+ Seed treatment with UUHF Psf -2 @ $10 \mathrm{~g} / \mathrm{kg}$ seed+ One foliar spray with UUHF Psf -2 @ $10 \mathrm{~g} / \mathrm{L}$ at the time of $50 \%$ flowering.

T6 = Soil application of value added vermicompost impregnated by fluorescent Pseudomonas isolate UUHF Psf $-1+$ Seed treatment with UUHF Psf -1 @ $10 \mathrm{~g} / \mathrm{kg}$ seed+ One foliar spray with UUHF Psf -1 @ $10 \mathrm{~g} / \mathrm{L}$ at the time of $50 \%$ flowering.

$\mathrm{T} 7=$ Untreated control

\section{Results and Discussion}

Evaluation for traits of biocontrol activity of fluorescent Pseudomonas spp. viz., siderophore production, $\mathrm{HCN}$ production and phosphate solubilisation

\section{Evaluation for phosphate solubilisation}

For evaluating phosphate solubilisation activity by collected fluorescent pseudomonad cultures, all the isolates were tested to solubilize the insoluble phosphate on Pikovaskaya agar medium. Out of 10 isolates, 03 isolates showed clear zones around the colonies indicated positive test for phosphate solubilisation (Figure 1A). The results are in agreement with the results of Parani and Saha (2012), Chinthala and Gundala (2012), Alemu (2013), Apastambh et al., (2016) and Yadav et al., (2016).

\section{Evaluation for siderophore production}

Out of 10 tested bacterial isolates, 3 isolates (UUHF Psf- 4, UUHF Psf- 2 and UUHF Psf 1)showing a clear orange halo around the bacterial growth on CAS medium indicating positive response for siderophore production (Figure 1B). The results are in agreement with Chinthala and Gundala (2012), Adhikari et al., (2013), Vanitha and Ramjegathesh (2014), Kamal et al., (2015) and Apastambh et al., (2016) who have earlier reported the production of siderophore by Pseudomonas spp.

\section{Evaluation for $\mathrm{HCN}$ production}

With respect to $\mathrm{HCN}$ production, 03 isolates (UUHF Psf- 4, UUHF Psf- 2 and UUHF Psf 1)showing positive response as revealed by the change in colour of filter paper (yellow to orange/ brick red or brown) lined on lid of media plates (Figure 1C).

With the increase in incubation period, colour of the filter paper tends to become darker indicating the increase in $\mathrm{HCN}$ production with increase in incubation period (4 to 7 days). Similar results of $\mathrm{HCN}$ production by PGPR have earlier been mentioned by Chinthala and Gundala (2012), Meera and Balabaskar (2012), Reetha et al., (2014) and Apastambh et al., (2016).

Evaluation against important endemic diseases under field conditions

The data pertinent to grain smut and brown spot diseases are presented in Table 2. 
Table.1 Description of host and location of rhizospheric soil samples used for isolation of Pseudomonas isolates for present study

\begin{tabular}{|c|c|c|c|c|}
\hline \multirow[t]{2}{*}{ S. No. } & \multirow[t]{2}{*}{ Host } & \multicolumn{2}{|c|}{ Location } & \multirow[t]{2}{*}{ Isolates } \\
\hline & & Village & District & \\
\hline 1 & Barnyard Millet & Phata & Rudraprayag & UUHF Psf-1 \\
\hline 2 & Barnyard Millet & Phata & Rudraprayag & UUHF Psf-2 \\
\hline 3 & Barnyard Millet & Korkhi & Rudraprayag & UUHF $P s f-3$ \\
\hline 4 & Barnyard Millet & Moun & New Tehri & UUHF Psf-4 \\
\hline 5 & Barnyard Millet & Daandachali & New Tehri & UUHF $P s f-5$ \\
\hline 6 & Barnyard Millet & Daargi & New Tehri & UUHF Psf-6 \\
\hline 7 & Barnyard Millet & Gaja & New Tehri & UUHF Psf-7 \\
\hline 8 & Barnyard Millet & Saabli & New Tehri & UUHF Psf-8 \\
\hline 9 & Barnyard Millet & Kalsi & Dehradun & UUHF $P s f-9$ \\
\hline 10 & Barnyard Millet & Kalsi & Dehradun & UUHF Psf-10 \\
\hline
\end{tabular}

Table.2 Effect of different treatments of fluorescent Pseudomonas isolates on grain smut incidence, brown leaf spot, grain yield and avoidable loss

\begin{tabular}{|l|l|l|l|l|l|l|l|}
\hline Treatment & $\begin{array}{l}\text { Grain } \\
\text { Smut } \\
\text { Incidence } \\
(\%)\end{array}$ & $\begin{array}{l}\text { Control } \\
(\%)\end{array}$ & $\begin{array}{l}\text { Brown } \\
\text { spot } \\
(\mathbf{G})\end{array}$ & $\begin{array}{l}\text { Control } \\
(\%)\end{array}$ & $\begin{array}{l}\text { Grain } \\
\text { Yield } \\
(\mathbf{Q} / \text { hac })\end{array}$ & $\begin{array}{l}\text { Increase } \\
\text { in grain } \\
\text { yield } \\
(\%)\end{array}$ & $\begin{array}{l}\text { A voidable } \\
\text { loss }(\%)\end{array}$ \\
\hline T1 & 20.00 & 61.29 & 5.33 & 36.01 & 15.27 & 8.83 & 8.12 \\
\hline T2 & 23.33 & 54.84 & 5.67 & 31.93 & 15.05 & 7.27 & 6.77 \\
\hline T3 & 22.66 & 56.14 & 5.33 & 36.01 & 15.66 & 11.61 & 10.40 \\
\hline T4 & 4.17 & $\mathbf{9 1 . 9 2}$ & 2.00 & $\mathbf{7 5 . 9 9}$ & $\mathbf{2 3 . 1 3}$ & $\mathbf{6 4 . 8 6}$ & $\mathbf{3 9 . 3 4}$ \\
\hline T5 & 16.67 & 67.73 & 3.00 & 63.98 & 18.00 & 28.29 & 22.05 \\
\hline T6 & 15.00 & $\mathbf{7 0 . 9 6}$ & 3.00 & $\mathbf{6 3 . 9 8}$ & $\mathbf{2 0 . 8 7}$ & $\mathbf{4 8 . 7 5}$ & $\mathbf{3 2 . 7 7}$ \\
\hline T7 & 51.67 & & 8.33 & & 14.03 & & \\
\hline S.Em \pm & 1.10 & & 0.267 & & 12.94 & & \\
\hline CD at 5 \% & 4.00 & & 0.823 & & 4.692 & & \\
\hline
\end{tabular}

Fig.1 Evaluation of fluorescent Pseudomonas isolates against (A) Phosphate solubilization, (B) siderophore production and (C) HCN production
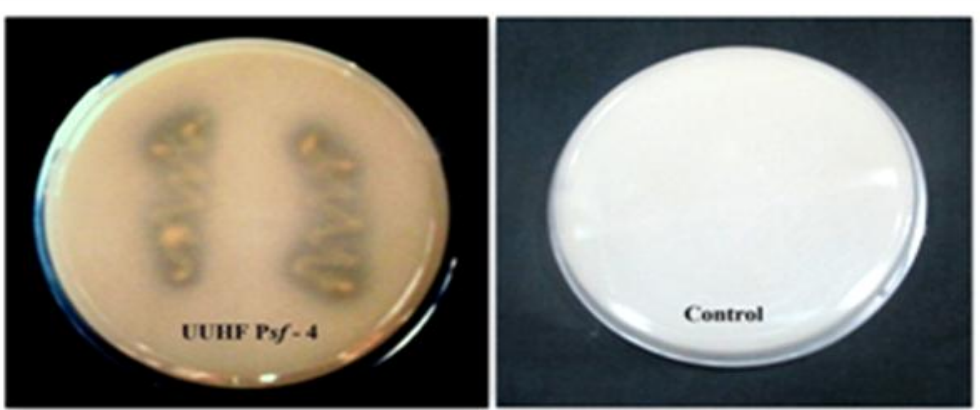

(A)

Phosphate Solubilization Int

or 

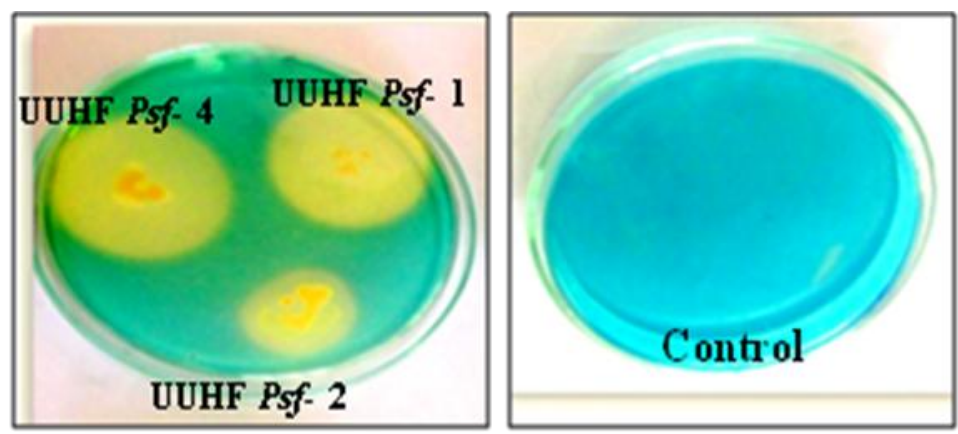

(B)

$$
\begin{aligned}
& \text { Evaluation of fluorescent Pseudomonas isolates for } \\
& \text { biocontrol traits (A) Phosphate solubilization (P- } \\
& \text { solubilizers were screened with a clear zone of } \\
& \text { solubilizattion round the bacterial growth } \\
& \text { (B) Evaluation of siderophore producing ability of } \\
& \text { Pseudomonas isolates on "Chrome azurol S" (CAS) agar } \\
& \text { medium. Development of orange halo around bacterial } \\
& \text { colonies indicates siderophore production. }
\end{aligned}
$$

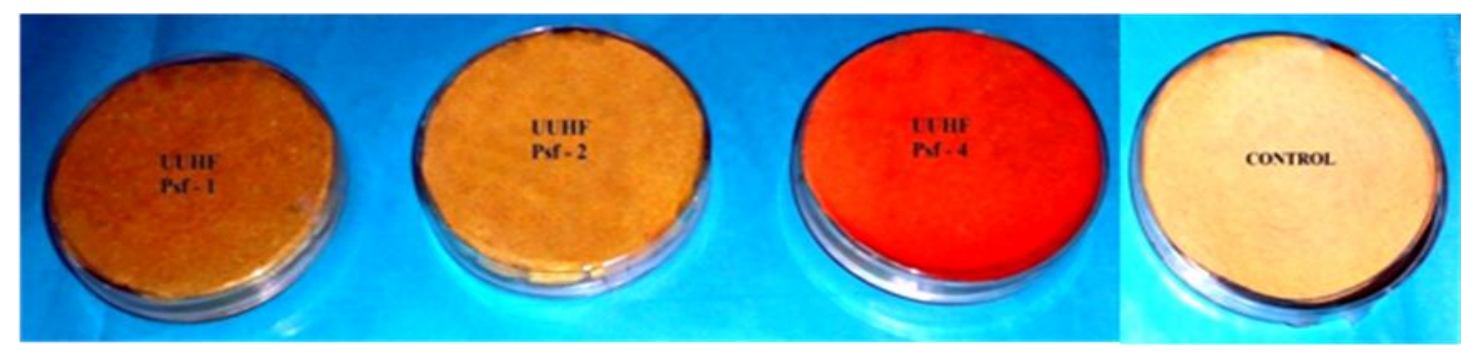

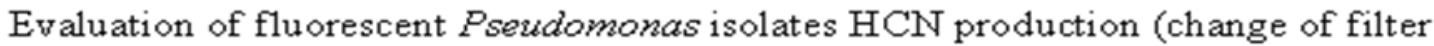
paper colour from yellow to orange indicates positive reaction.

Based on the data, it can be concluded that all the bio-control management treatments were effective in reducing the grin smut and brown spot diseases as compared to untreated control. However, maximum grain smut disease control $(91.92 \%)$ and brown spot disease control $(75.99 \%)$ was recorded in the treatment $\mathrm{T} 4$ (Soil application of value added vermicompust impregnated by fluorescent Pseudomonas isolate UUHF Psf- $4+$ Seed treatment with fluorescent Pseudomonas isolate UUHF Psf- 4 + One foliar spray with fluorescent Pseudomonas isolate UUHF Psf- 4 at the time of $50 \%$ flowering). Maximum grain yield (23.13 q/ha), highest per cent increase in grain yield $(64.86 \%)$ and highest per cent avoidable loss $(39.34 \%)$ was also recorded in the same treatment.

Treatment T6 (Soil application of value added vermicompost impregnated by fluorescent Pseudomonas isolate UUHF Psf $-1+$ Seed treatment with fluorescent Pseudomonas isolate UUHF Psf- $1+$ One foliar spray with fluorescent Pseudomonas isolate UUHF Psf- 1 at the time of $50 \%$ flowering) was next best treatment and recorded $70.96 \%$ grain smut disease control and $63.98 \%$ brown spot disease control, $32.77 \%$ avoidable los and $48.75 \%$ increase in grain yield. All the tested treatments were found economical and significantly superior in comparison to untreated control in suppressing the grain smut and brown spot diseases and enhancing the grain yield in Barnyard millet though the findings were better in treatment T4 (Soil application of value added vermicompost impregnated by fluorescent Pseudomonas isolate UUHF Psf- 4) in most of the parameters studied under present experimental conditions.

This research merits attention and could additionally open the avenue for the use of above mentioned fluorescent Pseudomonmas 
isolates in suppressing the most destructive diseases of Barnyard Millet at the mid hill regions of Uttarakhand.

\section{References}

Adhikari, A., Sarker, K., Roy, M. D., Bhattacharya, I., Mandal, T., Dasmohapatra, P. K. and Dutta, S. 2013. Siderophore mediated antagonism of fluorescent pseudomonads against soil borne plant pathogenic fungi In West Bengal, India. Afr. J. Microbiol. Res. 7(39): 4689-4700.

Alemu, F. 2013. Isolation of Pseudomonas fluorescens from rhizospheric soil of faba bean and assessment of their Phosphate solubility: in vitro study, Ethiopia. Sch. Acad. J. Biosci. 1(7):346-351.

Apastambh, A. R., Tanveer, K. and Baig, M. M. V. 2016. Isolation and characterization of plant growth promoting rhizobacteria from banana rhizosphere. Int. J. Curr. Microbiol. App. Sci. 5(2):59-65.

Chaube, H. S. and Sharma, J. 2002. Integration and interaction of solarization and fungal and bacterial bioagents on disease incidence and plant growth response of some horticultural crops. Plant Disease Research, 17: 201

Chinthala, P. and Gundala, P. B. 2012. Morphological, biochemical and functional characterization of Pseudomonas fluorescence strains isolated from forest litter of Seshachalam hill range. Int. J. Res. Pure. Appl. Microbiol. 3(1): 1-3.

Meera, T. And Balabaskar, P. 2012. Isolation and characterization of Pseudomonas fluorescens from rice fields. Int. J. Food, Agri. and Vet. Sci. 2(1): 113-120.
Miller, R. L. and Higgins, V. J. 1970. Association of cyanide with infection of birdsfoot trefoil by Stemphylium loti. Phytopathol. 60:104-110.

Parani, K. and. Saha, B. K. 2012. Prospects of using phosphate solubilizing Pseudomonas as bio fertilizer. Europ. J. Biol. Sci. 4(2): 40-44.

Rawat L, Singh Y, Shukla N, Kumar J. 2012. Seed biopriming with salinity tolerant isolates of Trichoderma harzianum alleviates salinity stress in rice: growth, physiological and biochemical characteristics. J Plant Pathol. 94:353365.

Rawat, L., Singh, Y., Shukla, N and Kumar, J. 2011. Alleviation of the adverse effects of salinity stress in wheat (Triticum aestivum L.) by seed biopriming with salinity tolerant isolates of Trichoderma harzianum. Plant Soil. 347: 387- 400

Reetha, S., Bhuvaneswari, G., Thamizhiniyan, P. and Mycin, T. R. 2014. Isolation of indole acetic acid (IAA) producing rhizobacteriaof Pseudomonas fluorescens and Bacillus subtilis and enhance growth of onion (Allimcepa. L). Int. J. Curr. Microbiol. App. Sci. 3(2):568-574.

Schwyn, B. and Neilands, J. B. 1987. Universal chemical assay for the detection and determination of siderophores. Anal. Biochem. 160:47-56.

Vanitha, S. and Ramjegathesh, R. 2014. Bio Control Potential of Pseudomonas fluorescens against Coleus Root Rot Disease. J. Plant Pathol. Microb. 5(1) DOI No. 10.4172/2151-7471.1000216.

Yadav, A., Yadav, K. and Vashistha, A. 2016. Phosphate solubilizing activity of Pseudomonas fluorescens PSM1 isolated from wheat rhizosphere. J. Appl. \& Nat. Sci. 8(1): $93-96$.

\section{How to cite this article:}

Laxmi Rawat, T.S. Bisht, Shambhoo Prasad, T. Samuel and Patro, S.K. 2018. Management of Important Endemic Diseases of Barnyard Millet (Echinochloa frumentacea L.) by the Use of BioControl Agents in Mid Hills of Uttarakhand, India. Int.J.Curr.Microbiol.App.Sci. 7(02): 64-70. doi: https://doi.org/10.20546/ijcmas.2018.702.009 